\title{
pro.posições
}

$e$-ISSN 1980-6248

DOSSIÊ: Empreendimentos sociais, elite eclesiástica e congregações religiosas no Brasil República: a arte de "formar bons cidadãos e bons cristãos"

\section{As congregações religiosas femininas francesas frente às opções de Secularização ou Exílio na França da Terceira República}

\section{"Catholic female religious congregations facing the secularization and exile in French Third Republic"}

Resumo: $\mathrm{O}$ artigo busca analisar o modo como as religiosas francesas enfrentaram, no período histórico correspondente à Terceira República (1870-1940) da nação francesa, processos adversos de fechamento dos institutos, da secularização e do exílio, os quais, de certa forma, concorreriam posteriormente para o desenvolvimento educacional feminino das nações onde elas se instalariam. Particularmente, o texto aborda o desenvolvimento e a expansão da Congregação Nossa Senhora de Sion, que chegou ao Brasil em 1888, como representativa das religiosas francesas que, tendo emigrado para vários países, contribuíram para a educação das jovens.

Palavras-chave: congregações religiosas femininas francesas, secularização, exílio, Nossa Senhora de Sion

Abstract: This article aims at analyzing the historical period of the French Third Republic (1870-1940). During this period French sisters were forced to face secularization, dissolution or exile, processes that, consequently, allowed them to contribute to the field of the women's education in the different countries they emigrated to. Particularly, this paper highlights the development and expansion of the Congregation of our Lady of Sion that arrived in Brazil in 1888, as a representative of the French religious who emigrated to various parts of the planet, where they effectively contributed to the education of young people.

Keywords: French female religious congregations, secularization, exile, Our Lady of Sion 


\section{pro.posıções \\ $e$-ISSN 1980-6248}

http://dx.doi.org/10.1590/1980-6248-2017-0108

\section{I - Introdução}

Ide e ensinai todas as gentes, batizando-as em nome do Pai, e do Filho e do Espirito Santo, ensinando-as a observar as coisas que vos mandei; e eis que estou convosco todos os dias até a consumação dos séculos

(Mateus, 28; 19-20)

Este artigo, que pretende relacionar inicialmente a situação política francesa durante a Terceira República nos finais do século XIX com a vinda das religiosas francesas ao Brasil, tenta demonstrar que as causas dessa saída da Europa se vinculam às pressões do anticlericalismo francês desse período. Claro está que não se excluirão aspectos políticos, missionários e o contexto histórico do Brasil nesse final do Império.

Historicamente, a França destacou-se como uma nação católica após as Guerras de Religião do século XVI. No final do século XVIII, no entanto, ela passaria por transformações ideológicas devido aos conflitos entre Estado e Igreja por ocasião da Revolução Francesa.

O Iluminismo, o desenvolvimento da ciência e da industrialização trariam modificações significativas na sociedade francesa, principalmente por meio da burguesia triunfante. Muitos autores franceses consideram o conflito entre a Igreja e o Estado francês como resultado de outras condições históricas pós-Revolução Francesa, num processo de secularização da sociedade e da separação entre a Igreja e o Estado no século XX.

Porém, na realidade, outras causas favoreceram a instalação das congregações religiosas no Brasil nesse período, como, por exemplo, a necessidade de a Igreja resgatar espaços fora da Europa, permitindo a expansão da ideologia ultramontana, e o interesse do Estado francês que, por meio de subvenções, responsabilizava as congregações religiosas no exterior pela difusão da cultura francesa, através do modelo escolar que difundiam (Petitjean, 1996; Xavier de Brito, 2010).

A análise aqui exposta concentrou-se no estudo dos efeitos históricos da laicização do ensino nos processos de secularização e do exílio das congregações femininas.

Paradoxalmente, alguns historiadores contemporâneos consideram que a Revolução Francesa foi motivadora do desenvolvimento das congregações femininas, pois, quando foi decretada a supressão das ordens monásticas pela Assembleia Nacional, elas seriam 


\section{pro.posições}

$e$-ISSN 1980-6248

teoricamente mantidas pelo Consulado e pelo Império. Napoleão tolerou o restabelecimento de certo número de congregações religiosas femininas sob o nome de "agregações" ou “associações" religiosas dedicadas à assistência hospitalar e ao ensino para as moças, já que os rapazes se beneficiavam dos estabelecimentos públicos.

Esse período conturbado não impediu, contudo, que a Igreja se desenvolvesse durante os governos subsequentes. No limiar da Terceira República (1870-1914),

havia na França, mais religiosas do que em qualquer outra época de sua história. A bonne søur fazia, tanto quanto o cura, parte do mobiliário paroquial .... Lembremo-nos alguns números impressionantes: em 1808, elas eram aproximadamente 13.000 e em 1880, 130.000. (Langlois, 1984, p. 384)

Segundo Claude Langlois, houve um grande desenvolvimento das congregações religiosas femininas no decorrer do século XIX: 400 novas congregações religiosas surgiram em em solo francês entre 1796 e 1880, sendo o período de 1820 a 1860 o mais fértil em fundações. Dentre elas, 5 se destacam por sua ascendência espiritual e sua riqueza material, como mostra a Tabela 1:

Tabela I: As cinco congregações mais ricas no final do século XIX

\begin{tabular}{|l|l|l|l|}
\hline \multicolumn{1}{|c|}{ Congregações } & $\begin{array}{c}\text { Renda per } \\
\text { capita }\end{array}$ & $\begin{array}{c}\text { Número de } \\
\text { membros }\end{array}$ & \multicolumn{1}{|c|}{ Atividade } \\
\hline Assomption (Paris) & $27000 \mathrm{~F}$ & 170 membros & Internato \\
Sacré-Cœur (Paris) & $24800 \mathrm{~F}$ & $140 \mathrm{membros}$ & Internato \\
Notre Dame de Sion (Paris) & $20800 \mathrm{~F}$ & 100 membros & Hospital especial \\
$\begin{array}{l}\text { Sainte Marie de l'Assomption } \\
\text { (Clermont) }\end{array}$ & $16000 \mathrm{~F}$ & & Internato \\
Fidèles Compagnes de Jésus & $15800 \mathrm{~F}$ & & \multicolumn{2}{|c|}{} \\
\hline
\end{tabular}

Fonte: Langlois, 1984, p.384

O século XIX foi o século mais fecundo em fundações femininas, nas quais a mulher se promove em relação aos papéis da sociedade.... A superiora geral possuía ampla faculdade de movimento e vasto poder de decisão.... As freiras diretoras de hospitais, de escolas, estão na vanguarda da valorização do "gênio feminino". As novas "virgens do trabalho" acompanham os necessitados do berço ao túmulo [ênfase no original] (Cabra, 2004, p.77).

Maria Jose Rosado Nunes (2009) também destaca os diferentes papéis que as religiosas passaram a desempenhar na sociedade, nesse período: 


\section{pro.posıções}

$e$-ISSN 1980-6248

http://dx.doi.org/10.1590/1980-6248-2017-0108

No final do século XIX, as freiras já se encarregavam de inúmeras tarefas necessárias à sociedade, particularmente no campo da educação, da saúde e da assistência social.... as freiras foram as primeiras a exercerem uma profissão, quando ainda a maioria da população feminina era do "lar". (p.483)

As fundadoras provinham, em sua maior parte, das classes dominantes. Pelo menos $22 \%$ delas eram oriundas da nobreza e $42 \%$, da burguesia, e possuíam uma herança cultural que lhes seria útil em outros espaços. "Se as congregações constituíram por assim dizer, uma estaca inicial da emancipação feminina, elas certamente também contribuíram para criar a forte ideia de que existem ocupações especificamente femininas" (Lagrée,1986, p.121).

A Congregação Nossa Senhora de Sion será tomada como exemplo devido às relações profissionais da autora deste texto como professora desse estabelecimento durante 40 anos; ao livre acesso que teve aos seus arquivos; e também à originalidade de seu carisma. Com efeito, ela é a única congregação católica a ter como missão o apostolado com aos judeus convertidos.

A Congregação das Irmãs de Notre-Dame de Sion integra essa expansão numérica de fundações femininas do século XIX na França. Fundada em 1842 como uma congregação de direito pontifício, suas primeiras Regras e Constituições foram redigidas pelo Padre Théodore Ratisbonne em 1847. Ela recebeu esse nome devido ao "nome bíblico da cidade de Jerusalém, fundada na colina de Sion, a sudoeste de Jerusalém, símbolo do povo de Israel. Tal palavra tem profundo significado tanto para os cristãos quanto para os judeus" (Colombo, 2013, p. 59). Hoje em dia, ela adquire o sentido de lugar do verdadeiro encontro, onde se reunirão "em um só corpo os filhos de Deus que estão dispersos” (Jó, 11:52).

\section{II - O Processo da Secularização}

Embora vos custe, é vosso dever abandonar o hábito religioso e continuar junto aos vossos alunos a missão de professoras e educadoras religiosas. Esse é o preço pelo qual salvareis a alma de vossos alunos e o ensino livre.

(Marie Mandin, sœur de Mormaison (Paisant, 2014, p.79) 


\section{pro.posıções \\ $e$-ISSN 1980-6248}

http://dx.doi.org/10.1590/1980-6248-2017-0108

\section{1) Antecedentes}

É preciso considerar a secularização como um processo que deve ser contextualizado na história, na situação política e na sociedade em questão. Como diz Cesar Ranquetat Júnior (2008), "a laicidade, assim como a secularização são processos socais distintos e devendo ser contextualizados histórica e socialmente" (p. 60).

Retomando historicamente o período pós-revolucionário francês, constata-se que a Igreja enfrentou grandes reveses, ora ganhando, ora perdendo seu poder. Napoleão Bonaparte e o Papa VII assinaram em 1802 a Concordata que restabeleceu o bom relacionamento com a Igreja, após os efeitos negativos da Constituição Civil do Clero de 1791. O Papa então reconheceu a República e renunciou aos bens subtraídos do clero pela Revolução. Os bispos passaram a receber pensões do governo e tornaram-se submissos ao poder público, através de suas nomeações. O catolicismo não era mais reconhecido como sendo a religião do Estado, mas continuava a ser a religião da maioria dos franceses.

Daí por diante, presenciamos um período bem controvertido, ora conservador, ora liberal no relacionamento entre o Poder Público e a Igreja, na medida em que o Estado ora desejava uma aliança, ora se opunha ao ultramontanismo clerical.

A análise que se expõe, no entanto, concentrou-se na França da Terceira República (1870-1940), notadamente na segunda metade do século, quando se desenvolveu no país um forte anticlericalismo decorrente das ideias nacionalistas e republicanas. A propagação das novas ideias contribuiu para acentuar o processo da laicização do ensino, que acabaria por marginalizar as congregações religiosas dedicadas à educação.

A partir do final do século XIX, mais precisamente em 1879, a Câmara dos Deputados votou favoravelmente às leis de Jules Ferry, Ministro da Instrução Pública da França. Iniciou-se então o período de exclusividade do Estado no setor universitário, limitando também o ensino e a direção de escolas às congregações não autorizadas. Em 1880, 81 e 82, novas leis iriam suprimir os jesuítas e estabelecer a gratuidade e a laicidade nas escolas primárias da nação. $\mathrm{O}$ ensino religioso seria substituído pela instrução moral e cívica. 


\section{pro.posıções}

$e$-ISSN 1980-6248

http://dx.doi.org/10.1590/1980-6248-2017-0108

A laicidade surgiu como uma ética e um conjunto de regras jurídicas que iriam coordenar as funções do Estado, dos serviços públicos e regulamentar a educação nacional.

Com o ministério de Émile Combes (1902-1905), a Igreja perdeu definitivamente sua influência sobre a juventude, e, a partir de então, tempos difíceis vieram para milhares de religiosos, que recorreram à clandestinidade ou se dirigiram para diversos países da Europa, ou mesmo para outros continentes.

Em 1905 as hostilidades se radicalizaram com a Lei de separação entre Igreja e Estado, que assegurava aos cidadãos franceses a liberdade de pensamento e de culto, colocava em pé de igualdade todos os credos e abolia o privilégio do clero católico de ser financiado pelo Estado. As leis de laicização, por sua vez, permitiriam a consolidação do poder republicano e do sistema público de ensino em todos os níveis.

\section{2) A secularização, difícil escolha}

Um país que pretendia ser o país das liberdades. Como se pode chegar a proibir a uma parte da população a tarefa de ensinar?

(Claude Langlois, 2014, p.10)

Compreendendo o termo secularização:

Historicamente, o termo foi usado no espaço jurídico-político na língua francesa, no final do século XVI, como forma de descrever a redução da ação do clérigo regular em função do Estado laico. Mais tarde foi utilizado no sentido de designar a espoliação das igrejas de seus direitos e propriedades.

Foi no século XIX, que o termo secularização passou a ser usado no campo filosófico ideológico, significando a redução drástica de influência da religião ou da Igreja sobre a educação, cultura e outros setores da vida social, movimento promovido por sociedades culturais e grupos intelectuais europeus. (Martelli, 1995, p.274)

$\mathrm{Na}$ França esse processo de secularização estendeu-se do final do século XIX aos primeiros anos do século XX, afetando os hospitais, os funerais, mas foi especificamente no terreno escolar que a luta foi mais viva, em função da importância que os franceses costumam dar à socialização das crianças e às pessoas a quem elas são confiadas. Assim sendo, pode-se 


\section{pro.posıções}

$e$-ISSN 1980-6248

http://dx.doi.org/10.1590/1980-6248-2017-0108

concluir, então, que as leis proibiram as irmãs de ensinar. "As que dispusessem de diplomas necessários poderiam se secularizar e abrir uma escola por sua conta, contando com a cumplicidade das personalidades locais e da população" (Langlois, 2014, pp. 29-30).

A secularização afetou os modos de vida e de trabalho das religiosas e dos religiosos mais antigos, que foram obrigados a abandonar o sistema de comunidade em que viviam e que lhes garantia a subsistência.

A volta à vida civil deixou aos antigos congregacionistas a possibilidade de encontrar emprego nas novas escolas livres desenvolvidas pelas dioceses ou por pessoas privadas, restando por outro lado a possibilidade de abrirem eles mesmos uma escola financiada por benfeitores, desde que possuíssem diplomas exigidos.... No entanto, para outros, principalmente para as irmãs, estaria apenas a possibilidade de empregar-se como dama de companhia ou preceptora nas famílias católicas, ou enfrentar a volta à sua família de origem. (Paisant, 2014, pp. 29-30)

Tempos difíceis afligiram então milhares de religiosos e religiosas que poderiam operar uma secularização pró-forma, na esperança de continuar a luta pela obra educacional de inspiração religiosa ou escolher uma secularização definitiva. Restava-lhes ainda, em última instância, a opção penosa da clandestinidade ou da expatriação para outros países da Europa ou de outros continentes. Aceitar a secularização permitiria aos ex-congregacionistas permanecer na França junto de seus pais idosos, continuar a ensinar ou reconverter-se a uma nova função. Deixar o país implicaria enfrentar o desconhecido, o isolamento e a incerteza do amanhã. Ainda assim, muitos iriam optar pela expatriação.

As religiosas que escolheram a secularização pró-forma passaram a usar trajes civis, eliminando os símbolos religiosos que as caracterizavam. Apesar de receberem seus documentos da secularização, elas continuaram, na verdade, a manter, tanto quanto possível, sua fidelidade aos votos e às regras. Apesar dos riscos da denúncia, do preço da renúncia ao hábito religioso e do abandono das comunicações com os ex-congregacionistas, esse tipo de secularização lhes dava a esperança de manter a continuidade da obra educacional confessional posteriormente e, porque não, a esperança de uma reintegração oficial.

A secularização efetiva provocaria, de fato, o desligamento dos Padres e das Irmãs de sua congregação, o desligamento dos votos e a volta à vida civil, com todas suas implicações. Oficialmente, o processo de secularização era individual e o(a) interessado(a) deveria solicitá-lo por escrito à sua superiora geral, depois ao bispo diocesano, o qual lhe entregaria então a ordem 


\section{pro.posıções}

$e$-ISSN 1980-6248

http://dx.doi.org/10.1590/1980-6248-2017-0108

de secularização. Nesse sentido, tal decisão adquiria a significação de um ato de obediência, não de uma escolha individual.

O "risco negro" sobre o nome de uma congregação no registro de secularização significaria efetivamente, segundo Chantal Paisant (2014), "a anulação de sua existência" (p.86). As irmãs se tornariam independentes de sua instituição e de sua hierarquia. Concretamente, no plano material, afetivo e existencial, a secularização passou a traduzir a pela perda do laço com a comunidade de origem e a ruptura com um estado de vida que elas tinham escolhido inicialmente e com o qual haviam se acostumado durante vários anos.Uma antiga Irmã de Mormaison ${ }^{1}$, Madre Henri de la Trinité, resumiu assim as explicações que lhe dera Monsenhor Catteau $^{2}$ :

As religiosas deixariam seus hábitos, se vestiriam como pessoas que vivem no mundo. Elas seriam desligadas de seus votos, exceto do voto de castidade ${ }^{3}$. Elas não teriam mais relações com seus superiores. Em sua nova situação, teriam que enfrentar sozinhas quaisquer dificuldades que surgissem. (Paisant, 2014, p.86)

No entanto, algumas Irmãs secularizadas não puderam suportar por muito tempo o isolamento imposto no contexto das incertezas do amanhã e acabaram entrando seja para a Visitation, para - Carmelo de Trappes, para as Irmãs de Saint Joseph de l'Apparition ou de Saint-Paul de Chartres, ou para Notre-Dame de la Sagesse, preferindo assim abandonar o ensino e voltar à vida religiosa, fosse numa comunidade de Irmãs enclausuradas, fosse como enfermeiras. (Paisant, 2014, p.121)

Para as antigas congregacionistas que não optaram pela secularização e preferiram continuar na França, restaram poucas escolhas: voltar para sua família de origem ou aprender novos ofícios como artesãs, confeiteiras, empregadas domésticas e catequistas a serviço das paróquias, ou criar pensões para senhoras ou estabelecimento para atender mulheres pobres. No entanto, para as mais idosas, as casas de repouso foram a única saída.

As congregações que já possuíam fundações em outros países, tais como o Sacré-Caur e a Sainte Famille de Bordeaux, recusaram de imediato a ideia da secularização e optaram mais facilmente pela partida para o exterior. Outras, como as Filles de Jésus de Kermaria, preferiram propor àquelas irmãs consideradas aptas a partir uma instalação fora das fronteiras francesas,

\footnotetext{
${ }^{1}$ As irmãs da Congregação dos Sagrados Corações de Jesus e de Maria, fundada na Vendeia em 1818 pelo abade Pierre Monnereau, são chamadas de irmãs de Mormaison.

2 Trata-se de Mons. Nicolas-Clovis-Joseph Catteau, bispo de Luçon desde 1877.
} 


\section{pro.posıções}

$e$-ISSN 1980-6248

http://dx.doi.org/10.1590/1980-6248-2017-0108

pois dispunham de acolhimento; mas, mesmo assim, as Superioras tentaram encorajar o sacrifício da secularização.

Essa opção pela secularização correspondeu a um processo pouco glorioso da história da França e muito estudada por Chantal Paisant, que revelou um período que foi "velado" dentro da imposição da laicidade nessa época da Terceira República, que culminaria em 1905 com a lei da separação entre Igreja e Estado. Milhares de republicanos apoiaram a privação de ensinar aplicada a numerosos e competentes professores e professoras, muitos dos quais iriam escolher o exílio como uma outra opção, na tentativa de buscar novas oportunidades para assegurar a vocação.

\section{III - 0 Grande Exílio}

Existe ainda, na história politica e religiosa da França, marcada por certo número de revoluções, de golpes de estado e de emigracõoes, um exilio quase completamente esquecido pela memória nacional; aquele de religiosos e religiosas nos inícios do século XX.

(Cabanel \& Durand, 2005, p.8)

Como já se viu aqui, a lei de julho de 1901 estabelecera uma política que afetava severamente as congregações religiosas, e seu texto foi aplicado rigorosamente pelo governo Combes a partir de 1902, mas sobretudo em 1904, quando se proibiu às congregações qualquer tipo de ensino. A partir dessa data, essa medida atingiu grandes proporções, levando as ordens religiosas a tomar atitudes divergentes: algumas decidiram solicitar sua secularização, outras escolheram a clandestinidade, outras ainda preferiram deixar a França e se expatriar.

Os religiosos e as religiosas de inúmeras congregações decidiram, num primeiro momento, instalar-se nos países limítrofes da França. Apenas mais tarde optariam pela imigração para lugares mais distantes, fosse na própria Europa ou nos novos continentes americano e australiano. O extenso trabalho de Laperrière (1996) sobre a imigração das ordens religiosas católicas francesas para o Canadá entre 1880 e 1914 mostra que, nesse período - mais particularmente entre 1901 e 1904, quando essa migração atingiu seu apogeu -, cerca de 1.265 ordens religiosas, femininas em sua maioria, se instalaram no Canadá, sendo 845 delas acolhidas por outras congregações já implantadas no local. 


\section{pro.posıções}

$e$-ISSN 1980-6248

http://dx.doi.org/10.1590/1980-6248-2017-0108

Após as últimas leis anticongregacionistas, "cerca de 160.000 religiosos e religiosas pessoas foram confrontadas a um desafio vital e dessas, 30.000 escolheram o exílio" (Cabanel, 1995, p.33).

A França foi a nação europeia que se notabilizara anteriormente pela expansão missionária, como bem assinalou Elizabeth Dufourcq (2009) em Les aventurières de Dieu, trois siècles d'histoire missionaire. Essa pesquisa cobre a história de 210 congregações religiosas francesas que saíram da França a partir do século XVII. Mais de 12 mil casas surgiram fora da Europa e mais de 200 mil irmãs instalaram-se além-mar. A Companhia das Filhas de Caridade de São Vicente de Paulo foi a maior delas e agrupava mais de 30 mil religiosas. Quantativamente, segundo Jacques Gadille (1994), esse mundo feminino era imenso. Foi, de fato, uma epopeia feminina inédita, que não encontra equivalência na história religiosa mundial.

As ciências humanas e sociais não realizaram muitas pesquisas sobre a expansão das religiosas missionárias europeias no continente sul-americano, embora o número de mulheres que se consagraram ao ideal religioso tenha sido elevado, sobretudo aquelas que contribuíram para difundir novas influências nos campos educacionais e culturais nos países onde se instalaram.

O trabalho mais recente foi realizado por Sol Serrano (2000), sobre as religiosas francesas que se dirigiram ao Chile entre 1837 e 1874.

No início do século XX, as emigrações acentuaram-se, principalmente porque a lei de 2 de julho de 1901, conhecida também como Lei das Associações, determinava que toda congregação educadora deveria solicitar autorização para ensinar.

Posteriormente as saídas que ocorreram entre 1901 e 1903 foram determinadas pela Lei das Penalidades, que estipulava multas e prisões para as congregações que abrissem escolas sem autorização ou que continuassem a exercer suas atividades após o decreto de fechamento; e mais adiante, também pela lei que veio a permitir que tais autorizações fossem recusadas.

Outras evasões resultaram da promulgação da lei de 7 de julho de 1904, quando Combes, presidente do Conselho, proibiu aos congregacionistas o ensino de qualquer ordem e qualquer natureza. Na França, a passagem da escola confessional congregacionista para a Escola Livre ou para a Escola Católica apenas se daria, de fato, após a lei de1905 que separou definitivamente a Igreja e o Estado. 


\section{pro.posições}

$e$-ISSN 1980-6248

http://dx.doi.org/10.1590/1980-6248-2017-0108

O processo de laicização somente foi considerado efetivo em 1965, quando os sacerdotes ou as irmãs constituíam pequena porcentagem do ensino católico, sem ocupar, no entanto, postos de comando. As escolas católicas passaram a ser dirigidas por leigas, que procuravam transmitir valores e princípios católicos de socialização. Os secularizados formariam os futuros professores leigos nas Escolas Normais organizadas às pressas, para formar educadoras leigas.

A Bélgica, país limítrofe com a França, abrigou 526 congregações francesas em setembro de 1907, seguida pela Espanha que acolheu 300 mil religiosos. O Canadá recebeu aproximadamente de 2 mil deles e Fribourg, na Suíça, cerca de 500 a 700 religiosos, segundo Patrick Cabanel (2005).

O Brasil foi considerado "coqueluche" na época e chegou a acolher 2.944 religiosas até 1920 (Cabanel, 2008, p. 20). Importante considerar que o exílio foi visto, sim, como uma opção triste e difícil inicialmente, mas, por outro lado, a questão missionária foi uma opção considerável, na medida em que incluía possibilidade da preservação da vocação, das atividades educativas e da expansão da cultura francesa.

\section{Tabela II: Congregações religiosas femininas francesas Datas da primeira implantação no Brasil}

\begin{tabular}{|c|c|c|c|c|c|}
\hline & $\begin{array}{c}\text { Antes de } \\
\mathbf{1 9 0 0}\end{array}$ & $\begin{array}{c}\text { Entre 1900 e } \\
\mathbf{1 9 1 4}\end{array}$ & $\begin{array}{c}\text { Entre 1914 e } \\
\mathbf{1 9 1 8}\end{array}$ & Após 1950 & Total \\
\hline $\begin{array}{c}\text { Número de } \\
\text { congregações }\end{array}$ & 7 & 10 & 6 & 18 & 41 \\
\hline Número & 4.485 & 1.284 & 619 & 190 & 6,758 \\
\hline Proporção & $68,1 \%$ & $19,5 \%$ & $9,5 \%$ & $2,9 \%$ & $100,0 \%$ \\
\hline
\end{tabular}

Fonte: Dufourcq (1984, pp. 45-76)

\section{O exemplo da Congregação Nossa Senhora de Sion}

A Congregação de Sion já havia passado por quatro superioras gerais quando decidiu enviar suas primeiras religiosas para o Brasil. Mère Marie Paul, superiora geral de 1885 a 1902, amiga da Princesa Isabel, filha do imperador brasileiro, recebeu uma solicitação da Condessa 


\section{pro.posıções}

$e$-ISSN 1980-6248

http://dx.doi.org/10.1590/1980-6248-2017-0108

Monteiro de Barros, em nome da sociedade brasileira e com apoio do Núncio Apostólico Monsenhor Spolverini, para o envio das irmãs de Sion ao Brasil.

Fundada em 1842, a Congregação de Notre-Dame de Sion constituiu-se em Paris a partir de um grupo de senhoras alsacianas que seguiram Théodore Ratisbonne a essa cidade. Essa comunidade, regularmente estabelecida sob a denominação de Nossa Senhora de Sion, teve em 1857 sua aprovação, através de um breve apostólico do Papa Pio XI (Mondésert, 1956, p.51).

Em 1853, Théodore conseguiu finalmente fundar o ramo masculino da congregação que tanto desejara: a Sociedade dos Padres missionários de Notre-Dame de Sion, hoje com sede em São Paulo (Brasil) e casas na França e em Israel.

O primeiro estabelecimento de ensino da congregação feminina foi instalado em 1851 em Grandbourg, cidade vizinha a Paris, com seis alunas internas. A Casa matriz foi inaugurada dois anos mais tarde na Rue Notre-Dame des Champs (Gème arrondissement), no centro de Paris. Quatro anos depois - após a consolidação das casas instaladas em Grandbourg (1851) e em Paris (1853) -, a partir de 1856, iniciou-se sua expansão internacional, com um estabelecimento fundado em Constantinopla e outro em Jerusalém.

Nos anos 1860, o clero inglês propôs ao Padre Ratisbonne fundações em terras britânicas, respectivamente em Bayswater (1861) e Worthing (1862). Sucessivamente, no final do século XIX e início do século XX, vários países veriam surgir novos estabelecimentos sionenses. No período 1843-1964, foram fundados 65, 53 dos quais, ou seja, $82 \%$ deles se situavam no exterior - Ásia, África Oriente Médio, Europa, América Latina, América do Norte - e apenas 12 na França. A Tabela III ilustra essa distribuição.

Nessa expansão, é preciso destacar que a partida das irmãs de Sion, determinada pela situação política da França nesse período do século XIX, foi ao encontro dos desejos da oligarquia brasileira, admiradora da cultura francesa e preocupada com a situação precária da educação no Brasil, mormente em relação às jovens.

Por ocasião do VII Capítulo Geral, em 1903, a congregação contava aproximadamente com 1.159 irmãs e 115 noviças. As leis de 1901 e 1904 provocaram o fechamento destes estabelecimentos escolares na França: Grandbourg, Paris, St Omer, Marseille, Royan. Nessa época, as superioras recusaram fortemente a ideia de secularização, a maior parte das Irmãs educadoras se expatriou. Após um processo de um ano, cujo julgamento foi confirmado em 7 


\section{pro.posições}

$e$-ISSN 1980-6248

de março de 1906, a congregação foi reconhecida como uma congregação missionária, podendo, desse modo, salvar seus centros de retiro espiritual e seu noviciado (Paisant, 2014, p. 353).

Tabela III - Estabelecimentos de Notre-Dame de Sion segundo o tipo e a localização

\begin{tabular}{|c|c|c|c|c|}
\hline $\begin{array}{c}\text { Grupos de } \\
\text { Comunidade }\end{array}$ & Casas & Colégios & Centros & Total \\
\hline América Central & 6 & 2 & 1 & 9 \\
\hline Austrália/Filipinas & 13 & 3 & 1 & 17 \\
\hline Brasil/Argentina & 14 & 5 & 2 & 21 \\
\hline Canadá/EUA & 30 & 3 & - & 33 \\
\hline Europa & 30 & 6 & - & 36 \\
\hline Mediterrâneo & 15 & 3 & 1 & 19 \\
\hline Romênia & 12 & - & 1 & 13 \\
\hline $\begin{array}{c}\text { Reino } \\
\text { Unido/Irlanda }\end{array}$ & 15 & 1 & - & 16 \\
\hline TOTAL & 135 & 23 & 6 & 164 \\
\hline
\end{tabular}

Publicação anual da congregação Nossa Senhora de Sion: Status, Roma, 2012

\section{a) A vinda da Congregação de Nossa Senhora de Sion para o Brasil}

Se a situação político-religiosa da França favoreceu a saída das Irmãs de Sion do país, por outro lado, o desejo das oligarquias brasileiras, admiradoras da cultura francesa, e a precária situação da educação no Brasil foram fatores decisivos para a fundação dos colégios confessionais franceses neste país, no final do século XIX e início do século XX.

De um modo geral, até o fim do século XIX, não havia entre as famílias brasileiras uma preocupação com a educação escolar para as mulheres. A primeira legislação relativa à educação feminina data de 1827 e lhes assegurava apenas os estudos elementares. Porém o número de estabelecimentos era insuficiente, e o ensino ministrado, deficiente. Essa constatação é corroborada por europeus e americanos que visitaram o Brasil nessa época. Quando os nobres, os cafeicultores, os militares e os membros dos setores mais elitistas da sociedade sentiam necessidade de oferecer uma educação escolarizada para as jovens, enviavam suas filhas para estudar nos pensionatos e colégios parisienses.

Mas, desde meados do século XIX, antigas alunas do Sion de Paris e outras senhoras da alta sociedade brasileira fizeram insistentes pedidos para que uma congregação francesa viesse se instalar no Brasil, para evitar às suas filhas a separação e o custo de tal viagem. 


\section{pro.posıções \\ $e$-ISSN 1980-6248}

http://dx.doi.org/10.1590/1980-6248-2017-0108

As congregações religiosas francesas que emigraram para o Brasil estão associadas à fundação de colégios para a elite nas principais cidades brasileiras das regiões de Minas Gerais, Rio de Janeiro e São Paulo, locais de desenvolvimento da principal riqueza da época, a cafeicultura. Sua atuação

foi assim fundamental para o desenvolvimento da educação secundária das elites brasileiras. Emigraram para o Brasil durante o século XIX, jesuítas, lazaristas, maristas, setores femininos dessas ordens e diversas congregações femininas autônomas dirigidas por uma superiora geral. E a França foi o país que mais influenciou a expansão da rede de escolas destinadas às moças. (Xavier de Brito, 2010, p.38)

O Estado brasileiro apoiou a instalação dessas escolas católicas durante o Império e a República, visando, sobretudo, a atender os anseios da oligarquia cafeeira, que desejava proporcionar às suas filhas, no próprio país, uma educação católica conservadora ideal, que as preparasse para o cumprimento de seus deveres de filhas, esposas e mães. Essas escolas se tornaram, portanto, indispensáveis.

Os inúmeros colégios espalhados pelo mundo sempre foram uma fonte de renda para a subsistência da congregação, além dos investimentos em aluguéis e propriedades.

As bibliotecas das diferentes comunidades possuem precioso acervo, no qual se podem consultar relatórios, constituições ou diários, como os de Théodore Ratisbonne, os de SionGrandbourg e os das Irmãs de Sion do Brasil. A renovação do seu carisma após o Concílio Vaticano II a fez equipar-se com 11 centros de documentação e/ou centros bíblicos, entre os quais se destacam o Serviço de Informação e Documentação Judaico-Cristão (SIDIC) em Israel, gerido pelas irmãs; e o Centre d'Études et Bibliotèque des Cahiers Sioniens/SIDIC de Paris. Ambos possuem grande coleção de documentos sobre as relações judaico-cristãs.

\section{Considerações Finais}

O presente estudo permitiu comprovar a hipótese de que o exílio das religiosas francesas foi fator decisivo na vinda ao Brasil e que favoreceu o desenvolvimento da educação, inicialmente das jovens da elite brasileira no final do século. 


\section{pro.posições \\ $e$-ISSN 1980-6248}

http://dx.doi.org/10.1590/1980-6248-2017-0108

Tradicionalmente conhecedoras e experientes de missões missionárias, as religiosas francesas, segundo Elizabeth Dufourcq, não encontrariam dificuldades na emigração.

Historicamente, procurou-se relacionar as condições do movimento de secularização e do processo de exílio que se abateram sobre a França católica do século XIX e que, de certa forma, mudariam as condições de vida das congregações religiosas católicas, especificamente as femininas, intensamente estudadas por corresponder à longa experiência que a autora adquiriu junto delas no campo educacional, aqui no Brasil, particularmente com a Congregação Nossa Senhora de Sion, no Colégio Sion, onde exerceu o magistério durante 40 anos.

No entanto, é preciso salientar que os pesquisadores contemporâneos estão dando maior atenção à atuação de todas as congregações religiosas no Brasil. Entre eles pode-se destacar o trabalho realizado pela Professora Agueda Bittencourt, da Universidade de Campinas, sobre as Congregações Católicas, Educação e Estado Nacional, no período compreendido entre 1840 e 1950.

A história mundial e brasileira tem ultimamente dado maior atenção às pesquisas sobre as congregações religiosas femininas, destacando o papel dessas mulheres de vida consagrada, cuja história permanece, muitas vezes, ignorada.

E, como dizem Cabanel e Durand (2005):

- Como a França aceitou as perdas duma parte de suas elites religiosas e educacionais?

- Quais foram as consequências para as congregações e para a Igreja e para a França mesmo?

O Estado reconheceu ao menos, a amplitude das saídas e o risco que a política anticongreganista refletiu a imagem e os interesses da França? (p.16) 


\section{pro.posıções \\ $e$-ISSN 1980-6248}

http://dx.doi.org/10.1590/1980-6248-2017-0108

\section{Referências}

\section{Artigos e livros}

Cabanel, P. (Dir.). (2008). Lettres d 'Exil. Les Congrégations françaises dans le monde après les lois laïques de 1901 et 1904 (Anthologie des textes missionaires, p. 5). Turnhout, Belgique: Brepols.

Cabanel, P., \& Durand, J.-D. (2005). Le grand exil des congrégations religieuses françaises 19011914. Paris: Cerf.

Cabra, P. G. (2006). Breve curso sobre a vida consagrada. Tópicos de teologia e espiritualidade. São Paulo: Loyola.

Colombo, M. A. da C. (2013). Sion, da Belle Époque aos nossos dias. São Paulo: Colégio Nossa Senhora de Sion.

Dufourcq, E. (1984). Les aventurières de Dieu. Trois siècles d'histoire missionnaire française. Paris: Perrin.

Gadille, J. (1994, juin). Lyon et la mission lointaine. Missin, 20.

Lagrée, M. (1986). Annales de Bretagne et des pays de 1 'Ouest, 93(1),120-124. Paris: Presses Univesitaires de France.

Langlois, C. (1984). Le catholicisme au féminin. Les congrégations religieuses à supérieure génerale au XIXe siècle. Paris: Cerf.

Langlois, C. (2014). Préface. In C. Paisant, De l'exil aux tranchées 1901/1914-1918. Le témoignage des sœurs. Paris: Khartala.

Laperrière, G. (1996). Les congrégations religieuses de France au Québec, 1880-1914. Laval: Presses de l’Université de Laval.

Martelli, S. (1995). A religião na sociedade pós-moderna: entre a secularização e a dessacralização. São Paulo: Paulinas.

Mondesért, C. sj. (1956). Les religieuses de Notre-Dame de Sion. Lyon: Lescuyer et Fils.

Nunes, M. J. R. (2009). Freiras no Brasil. In M. Del Priore, \& C. Bassanezi (Orgs.), História das mulheres no Brasil (pp. 482-509). São Paulo: Contexto. 


\section{pro-posıções \\ $e$-ISSN 1980-6248}

http://dx.doi.org/10.1590/1980-6248-2017-0108

Paisant, Ch. (2014). De l'exil aux tranchées 1901/1914-1918. Le témoignage des sœurs. Paris: Karthala.

Petitjean, P. (1996). Entre ciência e diplomacia: a organização da influência científica francesa na América Latina 1900-1940. In A. I. Hamburguer et al. (Orgs.), A ciência nas relações Brasil-França (1850-1950) (pp. 89-120). São Paulo: EDUSP; FAPESP.

Ranquetat, C. (2008). Laicidade, laicismo e secularização: definindo conceitos. Tempo da Ciência, 15, 59-62.

Serrano, S. (2000). Virgenes viajeras. Diarios de religiosas francesas en su rota a Chile, 18371874. Santiago de Chile: Universidad Catolica de Chile.

Xavier de Brito, A. (2010). L'influence française dans la socialisation des elites féminines brésiliennes. Le collège Notre-Dame de Sion à Rio de Janeiro. Paris: L’Harmattan.

\section{Fontes eletrônicas - Internet}

Dufourcq, E. (1988). Approche démographique de l'implantationhors d'Europe des congrégations religieuses féminines d'origine française, 43(1), 45-76. Retirado em 10 de julho de 2015, de http://www.persee.fr/web/revues/home/prescript/article/pop_00324663_1988_num_43.

Lagrée, M. (1986). Claude Langlois. Le catholicisme au féminin. Les congrégations françaises à supérieure générale au XIXe siècle. Annales de Bretagne et des pays de l’Ouest, 93(1), 120-124. Retirado em 30 de julho de 2015, de http://www.persee.fr/web/revues/home/prescript/article/abpo_03990826_1986_nu m_93_1_3211_t1_0120_0000_2. 